I80 apart, and the third midway. Each ship should observe in succession at each area for a month or two, as continuously as possible. In any case, an overlap of two or three hours should be secured for each 'day's' observations.

The relation of potential gradient to sunspots has been dealt with by Dr. Bauer in various recent papers which have been discussed in NaturE. Dr. Mauchly refers on pp. 405-406 to the bearing of the ocean observations on this point. He says: "The mean values for each 3 -month period . . . show throughout the years beginning with I9I 5, first an increase to I9r6 or I9I 7 , and then a gradual and consistent decrease to the end of I92I. This is so closely in accord with what has been observed at land stations, where reliable or undisturbed data of required extent are available, as to leave no doubt regarding the reality and universality of this phenomenon" (l.c. p. 405); and again: "in all látitudes for which there were sufficient observations . . . the mean values observed on cruise VI (mean epoch $\mathrm{I}_{920} \mathrm{O}^{\circ}$ ) were from $\mathrm{I}_{5}$ to 20 per cent. lower than those observed in cruise IV. (mean epoch I9I6.2)" (l.c. p. 406). These statements should, however, be taken in conjunction with the following two: "It should be noted that all potential gradient values shown in the graphs and tables of this report are of the order of 20 to 25 per cent. greater than those given in the author's earlier papers" (l.c. p. 397) ; and "At that time (r920), owing to various causes brought on by the War, there had been no final determinations of the instrumental constants to be used for reducing to absolute values the results of the . . . observations made aboard the vessel " (l.c. p. 387). Apparently all the observational data depend on reduction factors got out during expedition No. VI., and these are apparently assumed to have been unchanged since I9I5. Those having experience in these matters may perhaps be pardoned a doubt whether the factors used in Dr. Mauchly's earlier papers were so much in error as he now supposes.
The general subject of sunspot influence is considered in more detail by Dr. Bauer himself, pp. 36r-384. The following statement (l.c. p. 38I) embodies his present opinions: "The general conclusion from the investigations based on land and ocean results . . . is to indicate with a high degree of probability that during the cycle of $19 \mathrm{r}_{3}-\mathrm{r} 922$ the atmospheric potential gradient increased with increasing sun-spottedness by at least 20 per cent. of its mean value for the cycle between the years of minimum and maximum sun-spottedness. The same statement applies with regard to measures of the diurnal variation and of the annual variation of the potential gradient." These conclusions are based on the results obtained by the Carnegie at sea and on the published data of the Ebro, Eskdalemuir, and Kew observatories. The methods employed seem practically the same as in Dr. Bauer's earlier papers on the subject. No notice seems to be taken of the criticisms which have appeared in NATURE, and no further vindication is supplied of the omission of the results from Potsdam, which gave a small decline in potential gradient with increased sunspottedness. The reason assigned for disregarding Potsdam is alleged uncertainty as to the reduction factor. But uncertainty on this ground has been denied by the Potsdam authorities, and it seems scarcely likely a priori to have been more serious than in the case of the ocean observations which Dr. Bauer seems to have no doubts about.

As considerable use is made of the amplitudes and phase angles of Fourier coefficients by both Dr. Bauer and Dr. Mauchly, it may not be amiss to point out that the calculation of these coefficients from data in which large n.c. changes exist and have not been eliminated is unsatisfactory from the mathematical point of view. Unless the n.c. change is very small as compared with the daily range the effect of its neglect may be serious, especially in the case of the waves of least amplitude.

\title{
The Formation of Lactic Acid in Muscle.
}

A VERY important advance in our knowledge of this fundamental process has been made by Prof. Meyerhof in continuation of his well-known researches on the subject. Last January he announced (in Die Naturwissenschaften, I4, Heft Io) that he had succeeded in extracting the enzyme responsible for the production of lactic acid from carbohydrates in muscle, and gave an account of its properties. He has now carried matters a step further (Die Naturwissenschaften, $\mathbf{r} 4,32$ ) and has been able to penetrate much more deeply into the mechanism of the change. The enzyme, obtained by extracting the finely divided muscle with isotonic potassium chloride solution at $-\mathrm{I}^{\circ}$ to $-2^{\circ}$ and then centrifuging, readily forms lactic acid from starch and glycogen at a rate about two-thirds of that of the spontaneous formation of the acid in minced muscle. It is separated by ultra-filtration into a beat-labile inactive residue and a stable filtrate-the previously known coenzymewhich reactivates this residue. The coenzyme can be obtained either from muscle or yeast, and its addition greatly increases the amount of lactic acid producible from an excess of glycogen. The hexoses and the disaccharides are scarcely attacked, whereas lactic acid is freely formed, and at nearly the same rate, from glycogen, starch, and various degradation products of starch.

Hexosediphosphoric acid, the monophosphoric ester obtained from it by partial hydrolysis (Neuberg), and the isomeric monophosphoric ester from yeast juice (Harden and Robison) are all attacked. This decom- position of hexosephosphoric acid into equivalent amounts of lactic acid and phosphoric acid is, however, independent of the presence of the coenzyme which is necessary for the decomposition of glycogen and starch.

The production of lactic acid, either from glycogen or glucose, is preceded by the formation of a hexosephosphoric acid, and the reason why glycogen is the more easily acted on appears to be that a reactive hexose is formed from it which is more readily esterified than glucose in its stable form.

Meyerhof, hoping to be able to accelerate the action on the hexoses, turned to yeast-that unfailing storehouse of physiological surprises-and met with astonishing success. By precipitating autolysed yeast with 50 per cent. alcohol he obtained a new activatordifferent from zymase, coenzyme, and insulin-which, when added to the mixture of muscle enzyme and the hexoses, increases the rate of lactic acid formation until it amounts to several times that of its production from glycogen and Io times that of the spontaneous production of lactic acid in minced muscle. The decomposition of glycogen, on the other hand, is scarcely affected.

At the same time the esterification of the phosphoric acid is still more accelerated, and the result is that during the first $\mathrm{I}_{5-30}$ minutes there is a rapid accumulation of hexosephosphoric acid, which continues so long as both hexose and free phosphoric acid are present. The rate of production of the acid then falls rapidly, and is followed, when the supply of both hexose and phosphoric acid is exhausted, by NO. 298I, VOL. I I 8$]$ 
a stage in which a slow production of lactic acid and phosphoric acid in equivalent amounts takes place. The hexosephosphoric acid formed is approximately equivalent in amount to the amount of lactic acid produced.

This state of affairs presents, as will be seen, the most complete analogy to what occurs in alcoholic fermentation, with the difference that in one case the product is lactic acid and in the other alcohol and carbon dioxide. There is the same great acceleration in the rate of the reaction, accompanied by the accumulation of hexosephosphoric acid, the same drop in the rate when the free phosphoric acid is exhausted, and the same succeeding slow rate of change. As in the case of alcoholic fermentation, fructose reacts much more rapidly than glucose. There seems to be no doubt that the same fundamental change is in progress in the two cases.

Meyerhof believes that the hexosephosphoric acid produced is converted whilst in statu nascendi into the final products-lactic acid or alcohol and carbon dioxide (or some precursor of these) and phosphoric acid.

As, however, the rate of esterification is greater than that of decomposition, some of the phosphoric ester becomes stabilised in the less reactive form in which it can be isolated.
In the intact yeast cell and the natural muscle there is no accumulation of hexosephosphoric acid, " probably because, as the result of an accurate coordination, the whole of the labile ester produced is fermented, and not only about one-half of it, as in the extracts.'

This explanation scarcely accounts for the approximate equivalence between the amounts of hexose decomposed and converted into the stable ester, and there is doubtless more yet to be learned on this point.

The striking similarity established by Meyerhof between the changes of carbohydrates in muscle and in the yeast cell is seen to be much closer than has been believed. The remarkable phenomena accompanying alcoholic fermentation are now duplicated in the case of lactic acid production, and it may reasonably be expected that most of the fermentative decompositions of the sugars will be found to be initiated in a similar manner.

It is a great achievement to have pushed the analysis of the production of lactic acid so far, and further results of this line of investigation will be awaited with the greatest interest.

Arthur Harden.

\section{A Royal Collection of Scientific Instruments.}

$A \mathrm{~N}$ interesting historical document is described by Mr. Robert S. Whipple in "An Old Catalogue and what it tells us of the Scientific Instruments and Curios collected by Queen Charlotte and King George III." (Reprinted from the Proceedings of the Optical Convention, r926. Part 2.) The catalogue, which has been preserved at the Kew Observatory, was prepared in 1770 or a few years later. A reproduction of the first page of the catalogue is given, the complete catalogue (319 entries), and a "Catalogue of Presents by Sundry Persons" (77 entries) being printed as an appendix to the paper.

Whilst the first catalogue is confined wholly to scientific apparatus and instruments, a large proportion being of the educational or teaching type, the 'presents' are mainly of the 'natural history' type, including such objects as ' a dried cat,' ' a lizzard in spirits,' ' fosils from Virginia,' ' two Batavia rats,' 'two spiders from Bardadoes,' etc. In the latter list the names of the distinguished donors are given.

Before describing the contents of the collection, Mr. Whipple gives an account of the foundation of the King's Observatory at Kew for the purpose of observing the transit of Venus in I769. Some of the instruments included in the catalogue were used in the observations, and the original notes (preserved in the Library of King's College, London) by Dr. Demainbray recording the observations are published, it is believed for the first time. King George III. acted as an assistant during the observations. Queen Charlotte and the Princes Ernest and George of Mecklenburg-Strelitz were present, and others taking part were Col. Desaguliers, Rev. Geo. Wollaston, Stephen Rigaud, Justin and Benjamin Vulliamy, Jeremiah Sisson, and John Cuff.

Full details are given of the instruments used. and of the observations made. It is interesting to read that " His Majesty the King who made his Observation with a Short's Reflecting Telescope, magnifying Diameters r7o Times, was the first who saw the Penumbra of Venus touching the Edge of the Sun's Disk." There is.a note afterwards to the effect that " his Majesty thinks he saw it before he gave his Signal to Doctor Demainbray, who attended at the Regulator. And that Mr. Sisson (fearful of giving a false Alarum) waited an Instant before he caused Mr. Cuff to ring the Bell."

$$
\text { NO. 298I, VOL. II 8] }
$$

The collection of instruments and apparatus as specified in the Queen's Catalogue, with other objects afterwards acquired, remained as a national collection in the Kew Observatory until $x 84 \mathrm{x}$, when the Government decided to discontinue the maintenance of the Observatory. Mr. Whipple gives in detail the circumstances leading to this decision, and the consequent distribution of the collection to various institutions and individuals.

Some of the instruments and apparatus which went to King's College, with a request that "they should be preserved together as a whole" (forming the George III. Museum), are described and illustrated. The present locations of some of these, as well as of instruments which went to other institutions, are given.

Of the larger instruments included in the Catalogue, perhaps the best known to the general public are the large eight-feet mural quadrant by Jeremiah Sisson, and the observatory clock by Benjamin Vulliamy. These have been exhibited for many years in the Science Museum at South Kensington. Of the transit instrument, which went to Armagh Observatory, only the object-glass and the mahogany stand for lifting and reversing the telescope are still in existence, the object-glass being used at present for testing planes. The lens and some parts of the five-feet " astronomical sector in dome," as well as the six-inch telescope (probably that used by the King in I769) made by Short in $\mathbf{I} 745$, are still preserved at Armagh.

Mr. Whipple gives interesting evidence of the circumstances in which the valuable old microscopes were acquired by the late Sir Frank Crisp from the George III. Museum. The King's College authorities, though aware of the great historical value of the instruments, agreed to the transference only after much pressure, and "having been given the assurance that the Crisp collection was destined for the nation." Mr. Whipple adds: "The fact that the assurance was not fulfilled illustrates the importance of entrusting instruments or other objects of historical interest to a National Museum."

Since this interesting and valuable paper was read at the Optical Convention last April, the George III. collection, which was then still at King's College, has been transferred on loan to the Science Museum. 